\title{
DIÁLOGOS SOBRE A “UNIVERSIDADE DA VIDA”: DESCOLONIZANDO SABERES E PRÁTICAS DAS AGENTES COMUNITÁRIAS DE SAÚDE (ACS) NO ENFRENTAMENTO DA COVID-19
}

\section{DIALOGUES ON THE "SCHOOL OF LIFE": DECOLONIZING THE KNOWLEDGE AND PRACTICE OF COMMUNITY HEALTH WORKERS (CHW) FACING THE COVID-19 PANDEMIC}

\section{Ana Paula Marcelino da Silva}

marcelinopaula5@gmail.com

Bacharela em Filosofia (UFPB). Mestranda em Antropologia (PPGA/ UFPB). Integrante do Grupo de Pesquisa em Saúde, Sociedade e Cultura (GRUPESSC - CNPQ/UFPB).

ORCID: https://orcid.org/0000-0003-3564-3797

\section{Bruna Carla Cordeiro de Carvalho}

bccc@academico.ufpb.br

Bacharela em Direito (UFPB). Especialista em Saúde Pública (UFPB/ FioCruz). Mestranda em Antropologia (PPGA/UFPB). Integrante do Grupo de Pesquisa em Saúde, Sociedade e Cultura (GRUPESSC CNPQ/UFPB).

ORCID: https://orcid.org/0000-0002-5645-914X

\section{Ednalva Maciel Neves}

ednmneves@gmail.com

Professora de Antropologia do PPGA/UFPB, pesquisadora do Grupo de Pesquisa em Saúde, Sociedade e Cultura - GRUPESSC/UFPB. ORCID: http://orcid.org/0000-0002-3847-7301

\section{Maria José da Silva Pedro}

mariapedro4097@gmail.com

Agente Comunitária de Saúde e Conselheira Municipal de Saúde do Conde-PB.

只 ORCID: https://orcid.org/0000-0001-6549-4310

\section{(C) $\odot \Theta(0)$}

Esta obra está licenciada sob uma licença Creative Commons Attribution-NonCommercial-ShareAlike 4.0 International License.

\section{RESUMO}

O presente trabalho tem por objetivo demonstrar, por meio de relato da agente comunitária de saúde, as experiências locais da pandemia do coronavírus (SARS-Cov-2). De início, buscamos a horizontalidade 
do diálogo entre as autoras, reconhecendo os saberes envolvidos na produção de conhecimento. Em seguida, dialogamos sobre os limites do enfrentamento da pandemia para as agentes comunitárias de saúde (ACS) no contexto da Atenção Básica. Desde os entraves burocráticos encontrados por aqueles que inicialmente não eram considerados como linha de frente no combate da crise sanitária, até as dificuldades encontradas com relação às informações sobre a pandemia. As entrevistas revelaram como a autoridade dada pela comunidade, e por ela mesma, atravessou as barreiras institucionais dentro dos próprios órgãos, externalizando a autoridade de Maria José e sua resposta local à inação estatal perante as populações que mais necessitam de atenção. Tudo isso em contraponto entre os ditames dos saberes biomédicos e os saberes preventivos, que são o cerne da profissão de agente comunitário de saúde.

Palavras-chave: agente comunitária de saúde; pandemia; práticas de saúde; antropologia da saúde.

\section{ABSTRACT}

This work presents a reflection on local experiences of the pandemic of the novel coronavirus based on dialogues with a community health worker in Conde, a Brazilian coastal town. Initially, we sought for a horizontal dialogue between the authors - including the worker herself - acknowledging and drawing on her experience in the production of knowledge. Then, we have discussed the difficulties which Community Health Workers (CHW) underwent while facing the pandemic in the context of Primary Care. From bureaucratic barriers faced by those who were not initially considered essential frontline workers, to the difficulties in understanding the virus. The interviews with this $\mathrm{CHW}$ have shed light on how the authority given to her by the community - and by herself was a tool to overcome institutional barriers. This externalized her role as a protagonist and her local and prompt response to state inaction when attending to those in greater need, highlighting the contrast between biomedical knowledge and preventive healthcare, the latter of which is the cornerstone of being a Community Health Worker.

Keywords: community health worker; pandemic; health practices; pandemic; anthropology of health.

\section{INTRODUÇÃO}

Vida de ACS [sábado, 17 de abril de 2021, 10h45 horas, Google Meet]

Ouvimos a chegada de seu Biu na casa de Maria José,

E pergunta gritando: Cadê a vacina, hein?

Maria José responde: É pra semana, homem, hoje não. 
Seu Biu: A menina disse que era hoje.

Maria José: Hoje não, dia 17. Tá dia 17 no seu cartão? Acho que é dia 19.

Seu Biu: Não, é 17.

Maria José: Mas hoje o posto tá fechado. Só segunda-feira.

Seu Biu: Segunda?

Maria José: Até porque não tem vacina lá, viu?

[Seu Biu agradece e eles se despedem]

Em junho de 2020, buscamos dialogar com agentes comunitários de saúde (ACS) com o objetivo de trazer essa experiência profissional durante a pandemia para o conhecimento do público do Observatório Antropológico da Covid-19 ${ }^{1}$ da Universidade Federal da Paraíba (UFPB), na intenção de registrar as diferentes experiências e modos de estar no mundo durante a pandemia do novo coronavírus. Partimos do pressuposto de quea Atenção Primária à Saúde(APS) não foi devidamente mobilizada no enfrentamento da pandemia no Brasil, considerando sua capilaridade no tecido social do país. Nossa leitura é que as autoridades/ gestores sanitários, leia-se governadores e prefeitos, priorizaram o caráter biomédico-hospitalar aos adoecidos, em detrimento do enfrentamento preventivo centrado na interrupção da transmissão e em seus determinantes sociais. Esses processos de polarização (explicitados aqui em termos curativo/preventivo) se configuram em diferentes atuações políticas (sendo o negacionismo seu polo mais nefasto) de enfrentamento da pandemia no Brasil (MALUF, 2021).

Concordamos com Ventura et al. (2021) quando comentam que, de março de 2020 a janeiro de 2021, o governo federal utilizou de dispositivos legais como portarias, atos normativos etc., para configurar o que os pesquisadores classificaram como "uma estratégia institucional para disseminar o vírus” (VENTURA et al., 2021, p. 6). Além disso, eles destacam a discrepância federativa na gestão da crise sanitária, principalmente no que diz respeito ao debate da definição dos serviços considerados essenciais e, consequentemente, seu funcionamento apesar das medidas de isolamento. Não só em relação aos "serviços essenciais", mas a estratégia de (des)governança da pandemia buscava burlar "o alcance das medidas de proteção da saúde pública adotadas pelos Estados” (VENTURA et al., 2021, p. 32). Em torno das disputas judiciais que persistem até o momento, o Brasil alcança a marca dos 614.000 mortos (notificados) pela doença (The Center for Systems Science and Engineering/JHU, em 30.11.2021).

Encontramos com Maria José, agente comunitária de saúde, de forma remota ${ }^{2}$, é claro, pois estávamos em distanciamento social, medida instituída pelo governo estadual. Nosso encontro, mesmo à distância, foi marcado por uma empatia crescente. Éramos quatro mulheres que se encontravam para dialogar pela primeira vez acerca do fenômeno (SARS-Cov-2), que continua a afetar a vida de todas nós, seja pelo impacto na vida acadêmica e nas pesquisas, seja para nossa 
interlocutora, atuando no cuidado em saúde no chamado território da rede municipal de saúde.

O diálogo tinha como objetivo registrar as experiências da agente comunitária de saúde em seus territórios com ênfase no impacto e nas estratégias locais para o enfrentamento da pandemia, centrada nos domínios da atenção básica (AB). Nos interessava entender as práticas cotidianas preventivas e as demandas urgentes, mas também os protocolos e a reorganização do cuidado em razão da pandemia, envolvendo a dimensão política (tais como a definição de prioridades) e o suporte material (equipamento de proteção individual, por exemplo) fundamentais para atuação no território pelas equipes de saúde.

Qual não foi nossa surpresa em saber que nossa interlocutora era a presidente do Conselho Municipal de Saúde (CMS). Maria José atua como agente comunitária de saúde há 22 anos, seu ingresso se deu através de concurso público, e sua adesão e compromisso com o Sistema Único de Saúde (SUS) foram decisivos na sua escolha de morar no "seu território". Sua chegada à presidência do CMS se deu a partir de eleição, realizada no ano de 2019; assim, tornou-se presidente do Conselho Municipal de Saúde, representando os servidores públicos, mas também sua categoria profissional, os agentes comunitários de saúde.

Em abril de 2021, dez meses depois e mais de trezentos mil mortos ${ }^{3}$, retomamos o diálogo pensando sobre o inusitado dessa experiência de diálogo entre mulheres e como esse encontro remoto interrogava questões clássicas relativas ao fazer etnográfico e à antropologia. De fato, nós estávamos interessadas em deslocar as relações assimétricas de interlocução, pensando a partir dos diferentes interesses e perspectivas que trazíamos para o diálogo, seja o domínio de produção de conhecimento na interface antropologia e saúde, seja o domínio de atuação e suas imbricações.

Nós estimamos trazer a experiência local para conhecimento do público que acessava o Observatório Antropológico da Covid-19, registrando etnograficamente as experiências desiguais diante da pandemia. Consideramos também nossa implicação política em defesa do SUS e o entendimento de que o enfrentamento da pandemia passaria pelas Unidades Básicas de Saúde - Estratégia da Família e ACS - que atuam na localidade junto dos usuários cujas vidas precárias estavam sob risco (BUTLER, 2011; FASSIN, 2012). Já Maria José trazia a perspectiva de chamar atenção para a $\mathrm{AB}$ e para os dramas nos municípios e territórios, em termos de um lugar de fala, na dimensão política de que trata Ribeiro (2017). Seus referentes eram: a falta de informações e orientações acerca da covid-19; como as atividades rotineiras e os usuários seriam afetados pelo isolamento; equipamentos de proteção individual; profissionais de saúde que estariam entre os grupos de risco; o atendimento às pessoas com a doença covid-19. Ou seja, medidas a serem adotadas enquanto decisões políticas locais num 
contexto de ausência de gestão na esfera federal de Governo (com todas as implicações que isso representa) para o enfrentamento da pandemia.

Seguimos o pensamento de Clifford (2002, p. 55), para quem "[...] o termo informante não é mais adequado", na medida em que compartilhamos os interesses e as circunstâncias da etnografia. Assim, este texto está orientado por uma relação de colaboração entre as autoras, dedicadas a pensar sobre as (des)governanças na saúde no contexto de pandemia pelo novo coronavírus. Nesse sentido, o título destas reflexões é inspirado numa expressão utilizada por Maria José quando se referia às relações hierárquicas entre profissionais de saúde e às condições reais de vida das pessoas, de modo que a AB é a "universidade da vida", domínio das práticas de saúde.

Por isso, este artigo explora a reflexão acerca da descolonização do fazer antropológico a partir da experiência de coprodução de conhecimento realizada em contexto diferenciado de investigação. Nesse sentido, começamos por relativizar a exigência de produzir conhecimento antropológico atrelada/orientada por um protocolo de pesquisa, muitas vezes formal e normativo da reprodução de uma troca entre indivíduos ${ }^{4}$. Assim, a urgência de conduzir um conhecimento sobre a pandemia e sobre o domínio de atuação da ACS passou pela sistematização de objetivos e roteiro de diálogo distante do que chamamos de projeto de pesquisa. Assim, nós nos encontramos por meio de videochamadas e afeições, entre os espaços institucionais e o relacionais (KELLY; KECK; LYNTERIS, 2018).

Cabe ressaltar que não se trata apenas da temática sobre a experiência local e as dinâmicas relacionais com as pessoas no/do território, como expressivamente vivido durante a realização dessa reflexão, mas também sobre o deslocamento para o âmbito do conhecimento existente no território acerca da doença. Ponderamos também sobre o registro do "trabalho do ACS como um indicador sensível das disputas que se colocam no campo da APS", em especial quando se trata das formas de entendimento acerca dos elementos norteadores do cuidado exercido na Atenção Primária de Saúde (APS), a saber: o “[...] processo saúdedoença; o que é objeto da atenção à saúde; a definição do escopo e da abrangência dos serviços e das ações; assim como a configuração das práticas e do processo de trabalho." (MOROSINI; FONSECA, 2018, p. 263), num contexto marcado pelo desmonte do Sistema Único de Saúde (LIMA et al., 2019).

É importante ressaltar que o SUS tem sido atacado tanto em termos de retirada de investimentos quanto em termos de mudanças na regulamentação das práticas profissionais. Mudanças que atingem os princípios preconizados na Constituição Federal de 1988 e que, quando se trata das ACS, podem ser identificadas nos processos de retorno à contratação precária mediada por instituições de organização social, por exemplo (MOROSINI; FONSECA, 2018). 
Consideramos que vivemos uma experiência de descolonizar a interação ocorrida quando nos deparamos com o saber/conhecimento e a autoridade agregados por Maria José à nossa reflexão acerca das práticas de saúde na pandemia. De fato, reconhecemos que sua vivência é atravessada por uma representação do fazer em saúde, na qual a autoridade encontra-se situada na comunidade e não nas instituições públicas (MIGNOLO, 2007). A este respeito, nos alinhamos ao pensamento de Abu-Lughod (2018, p. 194) de que é preciso deslocar as "fronteiras entre si e o outro" no processo de produção do conhecimento antropológico, especialmente se reconhecemos os "sistemas políticos da diferença" (ABU-LUGHOD, 2018, p. 199) que mantêm as relações de poder e a desigualdade.

Assim, buscamos um diálogo que escapasse ao modelo assimétrico de produção de conhecimento, construindo conjuntamente com Maria José como agente de saber, enfrentando o desafio metodológico proposto no dossiê, dividindo a tela e a autoria deste texto entre mulheres. Cabe ressaltar também que usamos o "feminino universal", ancoradas no fato de que essa categoria profissional é majoritariamente composta por mulheres (ROCHA; BARLETTO; BEVILACQUA, 2013). Acrescente-se que se trata de uma reflexão acerca do trabalho na APS do município de Conde $^{5}$ do estado da Paraíba, a partir do enfrentamento da pandemia de covid-19 no Brasil.

\section{"EU SOU O SUS NA RUA": PRÁTICAS REFLEXIVAS E DINÂMICAS LOCAIS}

Por metonímia ou metáfora, portas são os acessos para algum lugar, aberturas por meio das quais indivíduos se movimentam para entrar e sair de um determinado lugar. SIMMEL (1996, p. 13) diz que "os fatores de dissociação e religamento [...] com a porta se concentram de forma mais igual enquanto prestação humana." Assim, nesse atravessar, é onde Maria José se encontra. Mulher. Mãe. Agente comunitária de saúde. Presidente-Conselheira Municipal de Saúde. Participante assídua do sindicato da categoria. Cidadã. Não à toa, ela declara: "Eu, como atenção básica, eu sou o SUS na região. [...] Eu sou a Porta de Entrada [...]". Para o SUS, o acesso ou a "porta de entrada" no sistema são as unidades básicas e as agentes comunitárias de saúde, distribuídas em territórios, que possibilitam seu conhecimento e atuação em 98\% dos municípios brasileiros (MOROSINI; FONSECA, 2018).

Bruna: Eu queria só confirmar contigo: você é presidente do sindicato ou do conselho municipal?

Maria José: Eu sou representante da categoria de agentes comunitários de saúde. Estou presidente do conselho municipal de saúde.

Esse lugar de fala trazido por Maria José, no nosso encontro, expõe sua pessoa pública, como presidente do Conselho Municipal de Saúde e 
representante das ACS. Em termos antropológicos, esse foi um desafio ético colocado às interlocutoras diante do princípio do anonimato nas relações de conhecimento, de modo que descolonizar teve como parâmetro esse ato político de reconhecer o lugar de fala de Maria José, estendendo sua participação à construção deste texto.

Por outro lado, esse lugar de fala nos remete à reflexão sobre a construção política do sistema nacional de saúde no Brasil, enquanto resultado da luta política de movimentos sociais que se reuniram em torno da Reforma Sanitária. Para esses agentes coletivos, a participação e o controle social são princípios a partir dos quais o exercício da cidadania em saúde toma seu caráter pleno, quando aos representantes dos usuários e dos servidores contribuem para a definição das políticas, estratégias e contornos do SUS no âmbito municipal de governo. O CMS é uma instância democrática, em especial quando se representa a categoria profissional num contexto de relações hierárquicas vigentes entre as profissões da saúde.

Nesse sentido, cabe lembrar que a normativa jurídica de implantação do SUS tem como marco legal a Lei Federal $n^{\circ}$ 8.080/1990, que regulamentou o art. 196 da Constituição Federal de 1988, completando 30 anos em 2020. A redação constante na Carta Magna possui como cerne a expressão: "a saúde é um direito de todos e dever do Estado", nesse sentido, cabe ao Estado brasileiro - em suas diversas esferas federativas - promover políticas públicas para a garantia desse direito humano fundamental. No entanto, entre a potência semântica da interpretação da lei e a efetividade das ações estatais para promoção da saúde e redução dos riscos de adoecimento, existe todo um aparato burocrático responsável por orquestrar essas ações (leis orgânicas, normas, protocolos, hierarquias etc.).

Segundo HERZFELD (2016), a compreensão da burocracia como fenômeno social abrange o entendimento de que existem "[...] áreas de tensão entre normas oficiais e valores sociais mais localizados" (HERZFELD, 2016, p. 13). Esses valores sociais giram em torno de questões mais amplas, como as de parentesco, por exemplo, mas, sobretudo, dos desdobramentos simbólicos em torno da noção de comunidade. Surge então a necessidade de organizar, de dentro do sistema burocrático, formas de suavizar as tensões existentes entre o Estado e a comunidade.

Do ponto de vista institucional, Silva e Dalmaso (2002) apontam, como marco para o desenvolvimento de um sistema de saúde pública no Brasil, o Serviço Especial de Saúde Pública (SESP), que funcionou entre 1942 e 1960, e a Fundação Serviço Especial de Saúde Pública (F. SESP), ativa entre 1960 e 1990. No entanto, o documento também destaca a necessidade de treinamento profissional, por parte de médicos e engenheiros sanitaristas, "para a formação de enfermeiros de saúde pública e o treinamento de outros técnicos" (SILVA; DALMASO, 2002, p. 
23). Daí em diante, quanto mais "público" se tornava o sistema de saúde mais havia a necessidade de minimizar as dificuldades históricas de acesso da população aos serviços de saúde. A emergência dos Programas de Agentes Comunitários de Saúde (PACS) e do Programa de Saúde da Família (PSF), como nos lembram Morosino, Corbo e Guimarães (2007), despontam como estratégia para ampliação do acesso e do direito à saúde, a partir dos princípios de integralidade e equidade.

Mais que uma tentativa de descentralização de recursos, o surgimento do PACS e do PSF consistiram em tentativas de desburocratização do acesso da população aos serviços de saúde. Este processo, que começou com a instalação física da unidade básica de saúde na comunidade, só podia se completar com a necessidade quase ontológica da intermediação entre o serviço e a comunidade, concentrada na figura das agentes comunitárias de saúde. Instituído em 1990, com a criação do SUS, o PACS foi regulamentado apenas em 1997. Além da integração entre os profissionais da saúde, o programa busca reduzir os índices de adoecimento da comunidade através da orientação para práticas de cuidado e prevenção por meio do acompanhamento constante. Num país de dimensões continentais como é o caso do Brasil, a figura da agente comunitária de saúde é a ponte entre as demandas e necessidades da população e o enredo burocrático em que está inserido o dever estatal de garantir a saúde de todas e todos.

É aqui que aparece uma das mais fascinantes singularidades que fazem do SUS um modelo do ponto de vista das políticas estatais de cuidado, a figura das agentes comunitárias de saúde. Assim, ao tomarem o trabalho das ACS como "indicador sensível das disputas que se colocam no campo da APS", Morosini e Fonseca (2018, p. 263) apontam para a composição da categoria, sendo predominantemente composta por mulheres que residem no território, porém enfatizam as mudanças recentes no nível de escolaridade e no regime de contratação (com intensificação da terceirização e precarização do trabalho).

Enquanto prática profissional, a função de agente comunitária de saúde passou por diversas modificações ${ }^{7}$ que se entrelaçam com as próprias mudanças nos sistemas de saúde pública no Brasil, como também faz parte de um esforço mundial pela construção de uma saúde comunitária de nível global, a exemplo da Declaração de Alma Ata (PINTO et al., 2020). Desde a Constituição Federal de 1988 e as Leis Orgânicas da Saúde, a profissão de ACS foi se estruturando a partir de definições de diretrizes e exercícios da atividade com visitas domiciliares e remuneração. No entanto, no atual regime de governo, a promulgação da Portaria n 3.270, de 11 de dezembro de 2019, altera os incentivos e custeio referentes à implantação de agentes comunitários de saúde, baseando-se numa racionalidade empresarial que altera o reconhecimento do SUS como uma instituição pública democrática e universal. 
Instalada no Loteamento Carnaúbas, zona urbana do município de Conde, na Paraíba, a Unidade Básica de Saúde (UBS) Nossa Senhora da Conceição, que fica no bairro de mesmo nome, conta com onze ACS. A organização do trabalho das agentes se dá a partir das noções de território e de microárea.

Ednalva: Deixa eu lhe perguntar... a gente está falando de dois termos que para o SUS e a AB são importantes: microárea e território. Qual é a diferença entre eles?

Maria José: Microárea é o bairro, aquele pedacinho onde eu trabalho, certo. Território é toda região de abrangência do PSF, a gente fala "o território" ou área de abrangência. [Território] é toda aquela parte que a unidade básica de saúde trabalha, aquela região. Eu moro e trabalho no Loteamento Carnaúbas, que já está dividido com uma colega, pois eu tive que dar 39 famílias minhas - morrendo de pena, chorei para não dar, mas me obrigaram... que foi agregado ao PSF Nossa Senhora da Conceição, que está construído e inserido dentro de um bairro com o mesmo nome. Esse bairro tem 9 ACS, comigo são 10. E tem uma outra colega de uma outra unidade de saúde, de um outro bairro, que também está inserida aqui. Então, são 11 ACS. Esse é o nosso território de trabalho.

O trabalho de cada ACS se desdobra no acompanhamento da população do território. É neste momento que o modelo ideal de monitoramento, exigido pelo sistema burocrático de gestão da saúde brasileira, entra em choque com as dificuldades reais que as agentes enfrentam diariamente. Esse processo deixa explícita a distância entre números, tabelas, gráficos e outros indicadores socioeconômicos e os acontecimentos e necessidades da vida cotidiana em termos de políticas públicas.

No caso da Unidade Nossa Senhora da Conceição ${ }^{8}$, Maria José nos explica que trabalha com cerca de 300 famílias, conforme indicado pelas diretrizes de funcionamento do SUS para a atenção básica, além de dividir sua microárea com uma colega. É justamente a lida diária com os desafios de trabalhar com esse quantitativo de pessoas que ela aponta como principal dificuldade para um desenvolvimento satisfatório de suas atribuições profissionais, pois, mais que números sobre determinado recorte geográfico, são pessoas inseridas em contextos bastante singulares.

Ana Paula: Então, quantas ACS estão na equipe, são 11 ACS no território e 2 na sua microárea?

Maria José: São duas na minha microárea. Então, eu tirei 39 famílias para poder ficar só com 300, porque o Ministério preconiza somente 750 pessoas $^{9}$. Mas ele [o Ministério da Saúde] não conhece as áreas e as microáreas. Aí, não dá pra fazer um trabalho digno, com 300 famílias, nenhum ACS trabalha bonito, trabalha bem, trabalha com qualidade, respeito. A gente passa, não dá tempo para escutar as pessoas direito, aí 
não é o certo. Eu ainda luto dentro do meu município pela modificação dessa portaria do Ministério da Saúde. Eu acho que a ACS tem que trabalhar com, no máximo, 200 famílias para ter uma escuta de qualidade, para poder implantar políticas com uma melhor qualidade, usar as terapias integrativas, isso ajuda muito.

Ainda que as condições de trabalho não sejam as ideais, Maria José e suas colegas de profissão seguem em frente com sua rotina diária de cuidado. De fato, a Política Nacional de Atenção Básica (PNAB) aprofundou a precarização e a sobrecarga no trabalho, com impacto na assistência e na caracterização do seu objeto, como se pode encontrar na literatura (SILVA, 2020; ALVES et al., 2020).

Esse relato é um bom exemplo de como a legislação dá espaço para incompatibilidades dentro do próprio SUS, pois com o advento da Política Nacional de Humanização, instituída no ano de 2003, outros desafios são vivenciados, considerando tanto as demandas dos usuários quanto a forma de prestação de assistência pelos profissionais, valorizando os aspectos subjetivos e a interação na relação profissional e usuário. No que diz respeito especificamente à atenção básica, essa política apresenta algumas orientações para a promoção desse cuidado humanizado, como a integração de práticas terapêuticas no sentido de diminuir a utilização de medicamentos e a elaboração de planos terapêuticos individuais e coletivos de acordo com as necessidades observadas.

Mas, como nos disse Maria José, "O SUS, ele é lindo, eu que posso burocratizar ele, criar barreiras [...]" (2020). Essas barreiras legais, muitas vezes edificadas sobre a incerteza advinda da própria ideia de considerar as "subjetividades", impedem a promoção da política de humanização, como bem nos mostrou Maria José, ao falar especificamente da necessidade de uma escuta atenta às demandas dos usuários do serviço de saúde. No meio dessa disputa entre a legalidade e a realidade, estão milhões de Marias como a nossa, que, mesmo diante de barreiras praticamente intransponíveis, continuam seu árduo trabalho de levar o SUS às casas de cada brasileira e de cada brasileiro. Ser agente comunitária de saúde é atravessar diariamente a "ponte" que liga as cidadãs e cidadãos ao serviço público de saúde, ainda que, como veremos mais adiante, estejamos no meio de uma pandemia.

As múltiplas referências à Maria José corroboram sua atuação em campo. Desde que iniciou sua atuação profissional como ACS, Maria José sempre teve suas ações transpassadas por estruturas rígidas de poder. Ainda assim, ela foi construindo seus vários modos de agência nas entrelinhas dessas estruturas há mais de vinte anos. Conforme ela nos explica: “[...] em 1998, conheci a profissão de agente comunitário de saúde [...] aí, eu fiz um processo seletivo que tinha na época, entrei e estou aqui há 22 anos. [...] E eu já me infiltrei na secretaria de saúde [...] abriram as portas para mim na secretaria de saúde." (2020). 
Maria José é uma das cinquenta e quatro profissionais do município do Conde que são o elo entre os saberes comunitários/populares e os serviços de saúde pública, vinculando os seus à UBS. O cânone particular da nossa autora é que ela encarna os requisitos encartados na Lei $n^{\circ} 11.350 / 2005$, pois, na sua área geográfica de atuação, Maria José cumpre cada inciso de seus atributos como ACS, não se desatrelando de seu papel político como presidenta do Conselho Municipal de Saúde.

Se como preconizado, "[as] Visitas Domiciliares são a principal expressão da presença do ACS no território" (MOROSINI; FONSECA, 2018, p. 263-264) e podem ser consideradas como "[...] ação programada estratégica para a ACS prestar cuidados no domicílio, orientar as famílias, prevenir agravos, fortalecer vínculos e ampliar a visão das condições reais de vida e das interações das pessoas no contexto familiar e social." (ALVES et al., 2020, p. 61). Na conversa, percebemos que o trabalho vai além dos horários regulamentados e, muitas vezes, a situação se inverte, quando elas são procuradas pelas pessoas do território (como exemplificado no registro da epígrafe deste texto). A proximidade e disponibilidade são os elementos que tornam a ACS uma referência em saúde no território, seja para buscar uma informação, seja para situações mais graves, como o adoecimento por covid-19.

O que tem marcado a autoridade de Maria José, confirmado por ela aqui, é o crédito que atribui ao SUS, seu reconhecimento dos moradores como cidadãos e do seu trabalho como uma atuação que "importa-se" com o outro (BLANC; LAUGIER; MOLINIER, 2020). A defesa do atendimento das pessoas do/no território se dá tanto na atuação na Unidade de Saúde quanto no CMS. Para ela, conhecer os regulamentos e direitos da cidadania em saúde lhe permite deslocarse entre entes institucionais diferentes, incluindo desde membros da equipe multiprofissional de saúde, outras ACS, integrantes do CMS, gestores municipais, até o Ministério Público, entre outros. Uma relação que não se dá sem tensões, visto que rupturas e pactuações cotidianas ocorrem e afetam os moradores da microrregião.

Bruna: Como é a rotina normal com as 300 famílias, sem ser pandemia, como é o trabalho da ACS?

Maria José: O trabalho da ACS é pra ele ter um cronograma de trabalho de acordo com o número de famílias. Todo dia ter uma quantidade certa de pessoas para visitar [...] eu não consigo. Pelo fato de eu ter um número de famílias muito grande, então eu vejo as necessidades, as carências, os mais distantes... então, minha prioridade hoje, por eu ter um número populacional grande, trabalhar com 1.052 pessoas. Eu priorizo os idosos, hipertensos, diabéticos, minhas gestantes, minhas crianças [...] não consigo seguir um cronograma, mas o correto era esse, o que o ministério preconiza é esse, que a gente tenha um cronograma diário de visita, rua por rua, mas não dá pra gente fazer. É impossível. Então, eu vou de acordo com a necessidade. 
Apesar das dificuldades na manutenção da regularidade e qualidade da visitação, percebe-se que a rotina laboral de Maria José segue intrínseca à sua identidade como moradora e cidadã ativamente política da comunidade, apesar de ter 52 (cinquenta e dois) anos e se enquadrar no grupo de risco (hipertensa e fumante) nunca deixou o seu colete ACS fora do campo: "[...] entro em um supermercado, eu entro para comprar e vou fiscalizar [...]” (MARIA JOSÉ, 2020). É precisamente através das "realidades vividas na vida das pessoas" (KELLY; KECK; LYNTERIS, 2018) que a profissional atenta às condições reais de vida e às relações entre as pessoas da família.

Confiante sobre seu dever acerca das práticas de saúde, Maria José nos explica que a atuação da ACS vai além, sendo condição necessária para o cargo "não ter medo" dos desafios que se apresentam, de forma generalizada, no âmbito da ação social. Sendo "o SUS lá na rua" (MARIA JOSÉ, 2020), ela entende que é da ACS a prerrogativa de aproximar mais as margens do Estado (DAS; POOLE, 2004), logicamente levando em consideração o fato de que os múltiplos (e marginais) saberes e práticas também devem ser considerados nessa aproximação. Nesse sentido, chama a atenção para a natureza educativa do trabalho, voltado para a prevenção e promoção da saúde. A este respeito, Alves et al. (2020) apontam para a descaracterização do trabalho do ACS à medida em que incorpora ações curativas que são específicas do profissional técnico de enfermagem, como averiguar temperatura e pressão arterial, por exemplo, tal como preconizado pela PNAB (2017).

Logo, ainda que pontes não sejam rapidamente edificadas - porque as distâncias, materiais ou imateriais, quase sempre são determinantes - a agente comunitária de saúde flui entre as barreiras da burocracia estatal, o que faz de sua atuação um exercício contínuo de articulação entre a política e o institucional, fortalecida por sua autoridade construída junto à sua comunidade e às ACS. De fato, nossa autora reconhece a dimensão transformadora do trabalho no cuidado à saúde das famílias na microárea, na medida em que atua a partir de saberes e vivências locais.

\section{CONHECIMENTOS E ESTRATÉGIAS DE ENFRENTAMENTO DA PANDEMIA NO TERRITÓRIO}

O aparecimento de uma novalinhagem do novo coronavírus - aSARSCov-2 - desencadeou uma emergência sanitária no mundo todo. No dia 11 de março de 2020, a doença, que teve os primeiros casos notificados em Wuhan, na China, já havia se espalhado por 19 países, levando a Organização Mundial da Saúde (OMS) a declarar que o mundo estava passando por uma pandemia (MATTA et al., 2021; CASTRO, 2020) ${ }^{10}$. No Brasil, o diagnóstico daquele que seria considerado o primeiro caso ${ }^{11}$ da doença já indicava quem seriam as pessoas mais afetadas, tanto do ponto de vista sanitário quanto do socioeconômico. 
Ortega e Orsini (2020) observam que a falta de liderança por parte do governo central brasileiro foi um fator agravante da situação de emergência sanitária causada pela pandemia. De acordo com os autores, o negacionismo e a falta de ação por parte do governo federal foram intensificados justamente quando a exposição da população ao risco foi aumentada e a covid-19 foi adentrando os lugares mais recônditos do país, ameaçando povos tradicionais e matando mais de meio milhão de pessoas.

No município de Conde, o vírus chegou pelas pontas do serviço de saúde, justamente pela atenção básica, peça-chave do SUS, que continua sendo subutilizada mesmo diante do agravamento da situação de emergência sanitária.

Ana Paula: Maria José, você lida diretamente com a população, já encontrou com alguém que não acredite que o vírus exista? Como vocês lidam com isso?

Ednalva: Deixa eu perguntar também para Maria José porque tá na mesma situação. Maria José disse assim "que a população não teve medo e não teve preocupação". Aí era um ponto que eu queria saber dessa reação das pessoas.

Maria José: Sim, uma coisa leva a outra. Pra gente fica um pouco difícil, mas a população no começo achou que era brincadeira, que era invenção... "Não, isso é política"... Cidade pequena, o povo vive de política partidária. Seu fulano disse que isso não existe, seu Cicrano... Então, quando você tiver contaminado; veja, seu Fulano na sua casa. Quando a gente falava no começo muita gente achava que era ilusão. Eu, até como profissional, eu tive um erro no começo. O primeiro caso positivo do Conde quem bateu de frente, recebeu o paciente, fui eu. Estava despreparada, sem máscara, sem luva, sem nada. Não sabia que o rapaz era positivo. Ele sabendo do erro dele não se preveniu, fez uma festa, contaminou-se e chegou na unidade não falou. Eu recebi ele despreparada. Mas eu tenho uma segurança muito grande. Eu tenho uma certeza comigo que eu posso até pegar, mas não tenho medo. E aí a gente foi convencer esse primeiro. $\mathrm{O}$ município não estava adequado para fazer exames de tipo nenhum. Quando a gente começou a ver a população sem medo, mas alguns já estavam sintomáticos, a gente queria o exame. Isso foi no mês de abril. Em abril foi que o município foi começar a se adequar para poder dar um suporte à população. Ainda têm aqueles que não acreditam, que estão sem máscara na rua, quando está, a máscara tá protegendo o queixo. Como eu disse, o Conde me conhece e eu não conheço a metade. Então, eu trabalhei desde a primeira barreira sanitária, que foi na entrada do Conde, até a barreira na feira.

A partir de então, Maria José e alguns colegas começaram a mobilizar ações em torno do problema da política federal e sua operacionalização local na gestão da pandemia e pandemônio (AUGUSTO; SANTOS, 2020). Em reunião com a então secretária de saúde do município, 
procuraram articular políticas de contenção e gestão do problema para que não houvesse o agravamento da situação. Uma dessas políticas foi a de atendimentos por via remota, com a utilização de smartphones. Como as informações sobre prevenção da doença ainda eram escassas naquela época, essa foi a forma encontrada para preservar ao máximo a vida tanto dos usuários, que continuavam demandando atenção do serviço de saúde, quanto das profissionais, que permaneceram sendo as principais fontes de viabilização dessa demanda.

Barreiras sanitárias foram instaladas para melhor controle da movimentação dentro do território, as medicações eram encaminhadas por meio das visitas domiciliares, que foram reduzidas e circunscritas à área "peridomiciliar"12, não somente por orientações sanitárias, mas - principalmente - por ausência de equipamentos adequados para o trabalho em campo.

Paula: O que foi que mudou "depois da pandemia" no trabalho de vocês. Acredito que vocês estão trabalhando até mais, porque têm esse cuidado a mais por causa do novo coronavírus... Como está sendo agora?

Maria José: Quando a médica passa a medicação, a gente vai lá na casa, não deixa ele [usuário] vir aqui. Eles vêm na unidade quando é pra fazer o teste rápido; sem ser, é o ACS que leva todas as informações, é o ACS que vai até a casa [...] Então, é dessa forma que as ACS aqui do PSF Conceição estamos convivendo hoje em dia: atrás de um medicamento, de um teste rápido, pedindo uma coisa ou outra... porque a gente vê a necessidade da população. E a gente com coragem, amor e respeito por essa população [...] Muitas das vezes, a gente não tem o equipamento adequado, um EPI pra entrar. Botamos uma máscara e no máximo uma touca e "vambora"!

Ednalva: Maria José, deixe eu lhe perguntar uma coisa: todo mundo no seu território tem celular para que você possa manter um contato? E quem não tem celular, como é que você está conseguindo manter um contato?

Maria José: Quase todos têm celular, tem uma minoria que não tem. Essa minoria eu procuro vê-los. Eu vou na casa, eu vou até lá, não posso deixar descoberto, porque eu tenho uma área que não pega telefonia, fica dentro de uma mata. [...] Então, eu vou ver porque tem idoso. Quando eu vejo que não tem como entrar em contato comigo, eu procuro. E deixo os vizinhos mais próximos atentos. Se ver qualquer movimento, qualquer coisa estranha, se aquela pessoa se ausentar... a pessoa mais próxima entra em contato comigo para eu ir até lá. Não abandono, não tem como abandonar. $\mathrm{O}$ telefone não mostra tudo.

A reorganização do processo de trabalho acontecia simultaneamente às ações para o enfrentamento da covid-19, para isso, tornou-se necessária a constante capacitação dos profissionais. Assim, o Ministério da Saúde, por meio da Secretaria de Atenção Primária à Saúde (SAPS), publicou, 
em março de 2020, a primeira e última versão das "Recomendações para Adequação das Ações dos Agentes Comunitários de Saúde Frente à Atual Situação Epidemiológica Referente ao Covid-19"13, às quais poucas ACS tiveram acesso; todavia, tal conteúdo só reafirmava o local da ACS perante o SUS: o da orientação comunitária.

A busca ativa de pacientes, de casa em casa, que já era rotina para Maria José, amplificou-se ainda mais com a pandemia, como também centralizou-se nos casos relacionados à covid-19, potencializando os riscos enfrentados pelas agentes. O contato com as famílias, que muitas vezes se dava sem equipamentos adequados, utilizando por vezes próprios recursos (crédito de celular) para manterem-se seguras, revela as limitações das agentes que vivenciam a linha de frente do risco, e que são relegadas em favor dos serviços de Atenção de Média e Alta Complexidade.

Bruna: Maria José, você falou de EPIs. Vocês estão recebendo? Como está com relação a equipamentos de proteção e álcool (em gel ou $70^{\circ}$ ) no município do Conde para as ACS?

Maria José: Ele [o município] se preocupa muito com esses profissionais de lá. Na visão deles esses profissionais é que estão correndo risco, quem é da atenção básica não. [...] no meu entender, a atenção básica é quem corre o maior risco.

Paula: O pessoal fala muito em linha de frente, mas vocês estão numa linha talvez mais à frente do que o pessoal do atendimento médico. Porque vocês estão em contato com pessoas que vocês não sabem que têm o vírus ou não. Como é que está sendo isso, como as informações estão chegando até você?

Maria José: [...] Para atenção básica em si a secretaria recebeu 200 testes e para o conselho municipal de saúde foi informado que os testes iniciaram pela atenção básica, mas não começaram, começaram pelo pronto atendimento.

Dialogamos com Kelly, Keck e Lynteris (2018), quando alegam como a atenção antropológica sobre as experiências locais dos eventos epidêmicos é promissora para a análise crítica e para interrogar os diferentes impactos sociais da resposta ao surto. Aqui, valorizamos os aspectos da experiência vivida e das formas de intervenção política da atuação da ACS, no seu território e no espaço institucional do Conselho Municipal de Saúde, que são formas de intervenção que resguardam a política da vida no contexto local, apesar das incongruências da gestão federal da pandemia. Essa reflexão é inspirada no relato de Maria José sobre sua luta para o reconhecimento e garantia do acesso à vacinação da categoria profissional que representa, que vai ao encontro da comunidade de "casa em casa", conforme sua própria regulamentação ${ }^{14}$. Desta forma, as ACS não foram consideradas como profissionais que 
estavam na "linha de frente" do enfrentamento da covid-19, seja pela não inclusão da categoria como prioritária para o fornecimento de EPIs, seja no seu não reconhecimento como grupo prioritário na vacinação.

Bruna: Sobre a vacinação... a sua categoria profissional, agente comunitária de saúde, está inclusa no plano de vacinação, local ou federal? Você acompanhou o processo? Como foi isso?

Maria José: Chegou logo para os profissionais de saúde, né? E a gente entendeu que a gente estaria no meio desse povo... Só que aí [...] disseram [...] "não... vocês não estão na linha da frente". Eu disse: "Não, como? Se o primeiro caso de covid quem pegou fui eu? Foi da minha microárea? Eu sem luva, sem máscara. Eu que fui levar medicação, eu fui cuidar, eu fui fazer teste rápido nas casas com a enfermeira, eu que trazia... Como é que não tô na linha da frente?". "Não, porque os profissionais do Pronto Atendimento (PA), enfermeiro, médico..." [...] "Sim, mas o paciente para chegar na unidade sou eu que levo!" [...] faço parte do sindicato dos agentes comunitários de saúde daqui do Estado da Paraíba (SINDACS), o sindicato entrou numa batalha com a CONACEN/CONASS, todos os conselhos, em um final de semana, e na segunda-feira foi publicada uma portaria, onde comprovava que a gente estava na linha da frente. Automaticamente, mandei para subsecretaria [...] ela já fez um cronograma, e aí eu fiz questão de registrar as ACS tomando vacinas, tomando suas doses, e também falei com meus colegas que era necessário que eles tivessem esse compromisso, de cobrir o horário e tomar vacina, porque não é uma vacina rotineira, igual as que a gente tem.

A pandemia de covid-19 evidenciou, ainda mais, as diversas fragilidades socioeconômicas do Brasil. Se antes as desigualdades sociais e raciais ficavam camufladas pela naturalização do cotidiano, o cenário da crise sanitária não será esquecido, especialmente pela visibilidade dada ao SUS como um sistema universal voltado para garantir a máxima cobertura diante de situações críticas e cotidianas. Por isso, reacendeu a defesa do SUS como direito social e como estratégia política de atenção em saúde. Como vimos, um dos grandes diferenciais que fazem do SUS uma referência no mundo é a presença, no mais amplo sentido, das agentes comunitárias de saúde que, como Maria José, têm a experiência necessária para fazer uma leitura crítica e precisa da situação, tomar decisões e agir a partir disso.

Essas profissionais carregam consigo conhecimentos que devem ser cada vez mais agregados ao SUS, pois fortalecem a relação da população com o sistema de saúde, permitindo o pleno exercício do direito constitucionalmente garantido, o direito à saúde. Especificamente no caso da pandemia, em que foi notória a falta de uma estratégia de gestão que garantisse a segurança sanitária dos brasileiros e brasileiras, a subutilização do conhecimento das ACS e da atenção básica como um todo foi um dos fatores mais determinantes para que o país tivesse um números de óbitos e contaminados tão significativo. Ainda assim, a 
resistência de Maria José e de suas colegas trouxe resultados significativos, principalmente no que diz respeito à percepção da população sobre a gravidade da doença e a urgência de se efetivar os cuidados necessários para minimizar a possibilidade de contaminação.

Ednalva: Maria José, deixa eu te perguntar uma coisa. Você acha que a população tem mudado a visão dela em relação à pandemia, agora depois que tá nessa situação ainda mais complicada?

Maria José: Sim, tem mudado bastante, sim. Muita gente já mudou, Muita gente, porque eles viram que pessoas conhecidas morreram. O que dá o choque na população não é as pessoas pegarem o covid. O choque está em morrer o conhecido ou ele ser alguém querendo respirar e a pessoa sem conseguir. Então, muita gente mudou, bastante pessoas. Ainda tem gente que diz assim: “isso é bobagem!”. Eu encontrei com um rapaz que ele disse: "eu estou procurando este camarada". Eu disse: "tranquilo, você quer encontrar mesmo com ele?". Ele disse: "quero, quero dar um abraço nele". Eu disse: "então vou lhe dar dois lugares onde você vai encontrar com ele brincando: vá no Clementino, pode entrar lá, passe 10 minutos lá dentro e pode sair, agora não venha pro Conde mais não". Aí, três dias depois, ele disse: "a senhora é doida, minha mãe nem precisou ir pro Clementino, ela encontrou perto de casa". Eu digo: "e agora, você quer encontrar com ele?". Ele disse: "o diabo quer". Era um agricultor, debochando, achando que era brincadeira. Mas mudou muito, Ednalva, mudou bastante. Muitas pessoas hoje já têm um olhar, eles já andam mais de máscara.

Em meio a toda essa incerteza sobre a dimensão e gravidade do problema, muitas vezes fruto da infodemia (RUI, 2021), as chamadas fake news, que foram determinantes para agravar a situação, as agentes comunitárias de saúde continuam sendo centrais para manter um elo de confiança entre a população e as informações oriundas das instituições de saúde. Mas esse elo depende sobretudo da sensibilidade dos gestores quanto ao melhoramento das condições de acesso e diversificação dos serviços de saúde.

Maria José: Eu acho que vai aumentar o número de casos assintomáticos, mas positivadas poucas, acho que em alguns casos é mais o psicológico das pessoas. Pedir para as pessoas ficar mais em casa e evitar aglomeração, essa parte de festas e eventos só retornar no fim do ano e as orientações de ficar em casa devem continuar. As prevenções também. $\mathrm{E}$ a gente como ACS deve continuar passando confiança, atendendo, vendo o que pode orientar, o que pode melhorar, até essa pandemia passar, porque o covid não vai acabar nunca mais, mesmo que crie uma vacina, sempre terá o próximo, mesmo que tenha a cura, sempre vai aparecer uma doença. Vai se tornar um sarampo, uma rubéola da vida, é cada um se prevenir e mudar a forma de higienização, de espaço. 


\section{EPÍLOGO}

Como visto neste trabalho, os saberes e vivências das ACS têm sido um vetor de mudanças no cuidado e no reconhecimento da cidadania em saúde no Brasil. Mesmo quando consideramos as alterações na Política Nacional de Atenção Básica, são as agentes comunitárias de saúde que continuam agindo como portas e pontes entre as necessidades e os serviços de saúde, fortalecendo o cuidado com a saúde da população.

O contexto trazido pela crise institucional e crise sanitária tem sido cruel na medida em que tem aprofundado as desigualdades estruturais que assolam a população brasileira, em especial o acesso e a garantia da integralidade do cuidado ofertado. Como nossa autora deixa entrever, esses processos são agravados pela rotatividade dos profissionais de saúde, flexibilização do trabalho em saúde e desconhecimento sobre o SUS e a atenção básica, resultando em tensões e negociações nas relações entre profissionais da equipe e na atenção à população.

A crise sanitária trouxe visibilidade ao papel do SUS para a população brasileira, como sistema universal e gratuito de promoção de saúde e cidadania. As ACS integram esse sistema, e sua atuação educacional e capilarizada no território e nas microáreas possibilita que famílias e pessoas em subcondições de vida possam receber alguma atenção. A atenção básica precisa ser acionada pelos gestores da saúde em suas estratégias de enfrentamento da pandemia, resistindo às investidas da necropolítica da (des)ação do governo federal e de outros gestores em diferentes níveis de governo.

O conhecimento que agregamos aqui vem do relato da experiência de vida de uma mulher, ACS, representante da categoria e presidente do Conselho Municipal de Saúde. Nesse processo de articular conhecimentos aprendemos sobre outros modos de vida das mulheres, sua atuação política e o impacto sobre muitas outras vidas.

É justo o conhecimento e a vivência trazida por Maria José que nos facultou praticar esse exercício reflexivo de coprodução de conhecimento. Assim, a descolonialidade argumentada por Mignolo (2007) transparece no relato como um "ato de desobediência epistêmica" que, por meio da autoridade e resistência de Maria José, nos permitiu conhecer sua experiência política, profissional e social.

\section{NOTAS}

1. O leitor encontrará nosso diálogo disponível no Observatório Antropológico da Covid-19/UFPB, no link: <https://www.instagram.com/p/CD7fNzkJyN3/>. Acesso em: 13 jul. 2021.

2. As entrevistas ocorreram de forma semiestruturada, com reuniões prévias entre as interlocutoras para definir os termos da conversa e, em seguida, foi feita a transcrição da videochamada gravada com anuência de Maria José. A primeira entrevista ocorreu em 16 de junho de 2020 e a segunda, em 17 de 
abril de 2021. No diálogo, buscou-se compreender quais foram as implicações sobre o trabalho da ACS e no contexto local ocorridas durante a pandemia, considerando a segunda onda de aumento de casos. As duas entrevistas foram analisadas, comparadas, discutidas e as reflexões resultantes foram apresentadas para Maria José no formato de artigo.

3. Nesse dia, o país contabilizou 13.900.134 casos e 371.889 óbitos por covid-19 desde o início da pandemia, segundo balanço do consórcio de veículos de imprensa. Disponível em: <https://g1.globo.com/bemestar/coronavirus/ noticia/2021/04/17/brasil-ultrapassa-371-mil-mortos-por-covid-paisregistrou-2865-mortes-em-24-horas.ghtml>. Acesso em: 17 jul. 2021.

4. Tal estilo etnográfico, em que o texto etnográfico se desloca além da dialogia (reprodução dramatizada da troca entre sujeitos) em direção a uma heteroglossia, que confere a todos os colaboradores o estatuto de autores, de modo coletivo (STRATHERN, 2017, p. 201).

5. O município de Conde, com população estimada de 25 mil habitantes (IBGE, 2021), está localizado na região metropolitana de João Pessoa-PB. De acordo com dados oficiais e históricos, no local onde hoje é o município de Conde viviam os indígenas Tabajara, até então administrado por missionários franciscanos. Posteriormente, com a ocupação holandesa no Nordeste, a aldeia do povo Potiguara, que também habitava aquela região, uniu-se aos parentes Tabajara, originando a região que hoje é a sede do município. Séculos depois, veio a emancipação política no ano de 1963, momento em que Conde deixou de ser apenas um distrito de João Pessoa e foi elevado à categoria políticogeográfica de cidade. Disponível em: <https://conde.pb.gov.br/portal/a-cidade/ historia $>$. Acesso em: 21 maio 2021. Atualmente, a cidade de Conde tem por base econômica o turismo/veraneio e o terceiro setor - serviços (depósitos de grandes empresas), em razão da sua localização privilegiada entre João Pessoa-PB e Recife-PE. A produção agrícola de subsistência está relacionada às populações tradicionais, indígenas e quilombolas.

6. O movimento "SUS NA RUA" surgiu em 2020, agregando profissionais de saúde, professores e pesquisadores do Brasil, atuando no âmbito da Educação Popular em Saúde, com o objetivo de mobilizar ações de enfrentamento à pandemia. Um grupo de whatsapp foi criado pelo "Movimento da Educação Popular em Saúde”, idealizado pelo professor Eymard M. Vasconcelos (CCM/ UFPB). Dentre as obras publicadas sobre o tema, destaca-se: VASCONCELOS, Eymard Mourão; PRADO, Ernande Valentino. A saúde nas palavras e nos gestos: reflexões da rede de educação popular e saúde. São Paulo: Hucitec, 2017. 7.Uma aproximaçãocomosantecedenteshistóricos da formaçãoe profissionalização da ACS pode ser encontrada em Morosino, Corbo e Guimarães (2007).

8. A UBS Nossa Senhora da Conceição conta com onze ACS, um médico, uma enfermeira, um dentista, um auxiliar de consultório dentário, uma técnica de enfermagem, uma recepcionista e um auxiliar de serviços gerais.

9. Maria José se refere à legislação existente acerca da adscrição da população no território das UBS, em especial a $\operatorname{PNAB}(2006,2017)$ que normatiza a cobertura e o vínculo da população com a UBS, mas que trouxe mudanças significativas, tais como: "flexibilização da carga horária de profissionais da Atenção Primária à Saúde (APS); a possibilidade de redução do número de Agentes Comunitários de Saúde (ACS) nas equipes; a não priorização da Estratégia Saúde da Família (ESF) do ponto de vista da indução financeira, 
além de mudanças nas atribuições comuns e específicas dos profissionais de saúde." (SILVA, 2020, p. 59).

10. Disponível em: <https:/g1.globo.com/bemestar/coronavirus/noticia/2020/03/11/ oms-declara-pandemia-de-coronavirus.ghtml >. Acesso em: 21 maio 2021.

11. A repercussão da primeira morte confirmada por covid-19 no Brasil deixou ainda mais explícitos problemas estruturais reconhecidos como desafios que se impõem ao SUS, ao mesmo tempo em que desenha o caminho que a doença percorreu até chegar ao país. Em 19 de março de 2020, a Secretaria de Saúde do estado do Rio de Janeiro confirmava a morte de uma idosa de 63 anos, diabética e hipertensa, que trabalhava como empregada doméstica, após contato com os patrões recém-chegados da Itália. Disponível em: <https://g1.globo.com/ rj/rio-de-janeiro/noticia/2020/03/19/rj-confirma-a-primeira-morte-porcoronavirus.ghtml>. Acesso em: 4 jun. 2021.

12. É uma expressão que se refere à frente, aos lados e ao fundo do quintal ou terreno do domicílio.

13. Disponível em: <http://www.saudedafamilia.org/coronavirus/>. Acesso em 17 jul. 2021.

14. Art. $3^{\circ} . \$ 2^{\circ}$ No modelo de atenção em saúde fundamentado na assistência multiprofissional em saúde da família, é considerada atividade precípua do Agente Comunitário de Saúde, em sua área geográfica de atuação, a realização de visitas domiciliares rotineiras, casa a casa, para a busca de pessoas com sinais ou sintomas de doenças agudas ou crônicas, de agravos ou de eventos de importância para a saúde pública e consequente encaminhamento para a unidade de saúde de referência. (Lei no 11.350, de 5 de outubro de 2006).

\section{REFERÊNCIAS}

ABU-LUGHOD, Lila; REGO, Francisco Cleiton Vieira Silva. A Escrita contra a cultura. Equatorial - Revista do Programa de Pós-Graduação em Antropologia Social da UFRN, v. 5, n. 8, p. 193-226, 2018.

ALLEBRANDT, Débora; MEINERZ, N.; Nascimento, P. G. (org.). Desigualdades e políticas da ciência. Florianópolis: Casa Verde, 2020. ALVES, A. D.; SOUSA, I. F. de; BIFF, D.; ELIAS, E. Impact of the reformulation of the National Primary Care Policy on the work process of Community Health Agents in a municipality in south of Brazil. Research, Society and Development, [s. 1.], v. 9, n. 10, p. e8039109198, 2020. Disponível em: <https://www.rsdjournal.org/ index.php/rsd/article/view/9198>. Acesso em 12 dez. 2021.

AUGUSTO, Cristiane Brandão; SANTOS, Rogério Dutra dos. Pandemias e pandemônio no Brasil. São Paulo: Tirant lo Blanch, 2020.

BLANC, Nathalie; LAUGIER, Sandra; MOLINIER, Pascale. O preço do invisível: as mulheres na pandemia. Por que as mulheres, onipresentes na luta contra a pandemia e seus efeitos não obtêm a visibilidade que elas merecem? A crise que nós vivemos é reveladora de nossa negação e desconsideração das atividades cotidianas. Dilemas: revista de estudos de conflito e controle social, Rio de Janeiro, p. 1-13, 2020.

BRASIL. Ministério da Saúde. Secretaria Executiva. Programa agentes comunitários de saúde (PACS). Brasília: Ministério da Saúde, Secretaria Executiva, 2001. 40p. 
BRASIL. Humaniza SUS. Ministério da Saúde. Secretaria Executiva. Núcleo Técnico da Política Nacional de Humanização. Brasília: Ministério da Saúde, 2003. 20p.

BRASIL. Ministério da Saúde. Secretaria de Atenção Básica. Departamento de Atenção Básica. Política Nacional de Atenção Básica. Brasília: Ministério da Saúde, 2006. Disponível em: <http:// dab.saude.gov.br/portaldab/pnab.php>. Acesso em: 21 ago. 2009.

BUTLER, Judith. Vida precária. Contemporânea - Revista de Sociologia da UFSCar, n. 1, p. 13-33, 2011.

CASTRO, Bárbara (org.). Covid-19 e sociedade: ensaios sobre a experiência social da pandemia. Campinas: UNICAMP/IFCH, 2020.

CLIFFORD, James. A experiência etnográfica: antropologia e literatura no século XX. Rio de Janeiro: Editora da UFRJ, 2002.

DAS, Veena; POOLE, Deborah. Anthropology of in the margins of State. Santa Fe: School of American Research Press, 2004.

FASSIN, Didier. O sentido da saúde: antropologia das políticas de vida. In: SAILLANT, Francine; GENEST, Serge. Antropologia médica: ancoragens locais, desafios globais. Rio de Janeiro: Editora Fiocruz, 2012. p. 375-390.

HERZFELD, Michael. A produção social da indiferença: explorando as raízes simbólicas da democracia ocidental. Petrópolis: Editora Vozes, 2016.

IBGE - INSTITUTO BRASILEIRO DE GEOGRAFIA E ESTATÍSTICA. Perfil do Município do Conde - Paraíba: estimativa populacional do ano de 2021.Perfil das cidades brasileiras. Rio de Janeiro: IBGE, 2021. Disponível em: <https://cidades.ibge.gov.br/brasil/pb/conde>. Acesso em: 01 jul. 2021.

KELLY, Ann H.; KECK, Frédéric; LYNTERIS, Cristhos. The anthropology of epidemics. New York: Routledge, 2018.

LIMA, Humberto Sérgio Costa et al.. SUS, saúde e democracia: desafios para o Brasil - manifesto de seis ex-ministros da saúde a propósito da 16 Conferência Nacional De Saúde. Ciência \& saúde coletiva, v. 24, n. 10, p. 3713-3716, 2019.

MAUSS, Marcel. Técnicas corporais. In: MAUSS, Marcel. Sociologia e antropologia. São Paulo: Cosac Naify, 2003.

MACIEL, Fernanda Beatriz Melo. Agente comunitário de saúde: reflexões sobre o processo de trabalho em saúde em tempos de pandemia de Covid-19. Ciênc. saúde coletiva, Rio de Janeiro, v. 25, n. 2, p. 4185-4195, out. 2020 . Disponível em: <http://www.scielo.br/ scielo.php?script=sci_arttext\&pid=S1413-81232020006804185\&lng $=e n \& n r m=i s o>$. Acesso em: 22 maio 2021.

MALUF, Sônia. Janelas sobre a cidade pandêmica: desigualdades, políticas e resistências. Tomo, n. 38, jan./jun., 2021.

MATTA, G. C.; REGO, S.; SOUTO, E. P.; SEGATA, J. (ed.). Os impactos sociais da Covid-19 no Brasil: populações vulnerabilizadas e respostas à pandemia [online]. Rio de Janeiro: Observatório Covid 19/FIOCRUZ, 2021. Disponível em: <https://doi.org/10.7476/9786557080320>. Acesso 13 dez 2021. 
MIGNOLO, W. D. Epistemic Disobedience: the de-colonial option and the meaning of identity in politics. Gragoatá, v. 12, n. 22, 2007. Disponível em: <https://periodicos.uff.br/gragoata/article/ view/33191>. Acesso $13 \mathrm{dez} 2021$.

MOROSINI, Márcia Valéria; CORBO, Anamaria D’Andrea;GUIMARÃES, Cátia Côrrea. O agente comunitário de saúde no âmbito das políticas voltadas para a atenção básica: concepções do trabalho e da formação profissional. Trabalho, Educação e Saúde, n. 5. v. 2, 2007.

MOROSINI, Márcia Valéria; FONSECA, Angélica Ferreira. Os agentes comunitários na atenção primária à saúde no Brasil: inventário de conquistas e desafios. Saúde em debate, Rio de Janeiro, v. 42, n. 1, p. 261-274, set. 2018. Disponível em: <https://doi.org/10.1590/010311042018S117>. Acesso 13 dez 2021.

ORTEGA, Francisco; ORSINI, Michael. Governing covid-19 without government in Brazil: ignorance, neoliberal authoritarism and the collapse of public health leadership. Global Public Health, 2020.

PINTO, Luiz Felipe; SORANZ, Daniel; PONKA, David; PISCO, Luís Augusto; HARTZ, Zulmira Maria. 40 anos de Alma-Ata: desafios da Atenção Primária à Saúde no Brasil e no mundo. Ciência \& saúde coletiva, v. 25, n. 4, p. 1178, 2020. Disponível em: <https://doi. org/10.1590/1413-81232020254.01012020>. Acesso 13 dez 2021.

RIBEIRO, Djamila. O que é lugar de fala? Belo Horizonte: Letramento/ Justificando, 2017.

ROCHA, Natália Hosana Nunes; BARLETTO, Marisa; BEVILACQUA, Paula

Dias. Identidade da agente comunitária de saúde: tecendo racionalidades emergentes. Interface, Botucatu, v. 17, n. 47, p. 847-857, 2013.

RUI, Taniele. Antropologia e pandemia: escalas e conceitos. Horizontes antropológicos, v. 27, n. 59, p. 27-47, 2021. Disponível em: <https://doi. org/10.1590/S0104-71832021000100002>. Acesso em: 13 jul. 2021.

SANTOS, Thayonara Marina da Silva. A qualidade somos nós: considerações sobre cuidado na atuação das Agentes Comunitárias de Saúdeem Mituaçu,Conde-PB.2020.70f.TCC(GraduaçãoemCiências Sociais) - Centro de Ciências Humanas, Letras e Artes, Universidade Federal da Paraíba - UFPB, João Pessoa, 2020. Disponível em: < https:// repositorio.ufpb.br/jspui/bitstream/123456789/17432/1/2019.2\%20 LIC \% 20 THAYONARA \% 20SANTOS\%20 A GENTES \% 20 COMUNIT\%C3\%81RIAS.pdf >. Acesso em: 13 dez 2021.

SILVA, Joana Azevedo da; DALMASO, Ana Sílvia. Agente Comunitário de Saúde: o ser, o saber, o fazer. Rio de Janeiro: Editora FIOCRUZ, 2002. SILVA, Thais Lacerda. Política Nacional de Atenção Básica 2017: implicações no trabalho do Agente Comunitário de Saúde. Saúde em Debate, v. 44, n. 124, p. 58-69, 2020. Disponível em: <https://doi. org/10.1590/0103-1104202012404>. Acesso em: 08 maio 2020. 
SIMMEL, George. A ponte e a porta. Revista de ciências sociais - política \& trabalho, n. 12, p. 11-15, 1996. Disponível em: <https://periodicos. ufpb.br/ojs/index.php/politicaetrabalho/article/view/6379>. Acesso em: 13 dez 2021.

STRATHERN, Marilyn. O efeito etnográfico e outros ensaios. Trad. Iracema Dullei, Jamille Pinheiro e Luísa Valentini. São Paulo: Cosac Naify, 2017.

VENTURA, Dayse et al. Boletim direitos na pandemia: mapeamento e análise das normas jurídicas de resposta à Covid-19 no Brasil, São Paulo: Conectas Direitos Humanos, n. 10, jan. de 2021.

SUBMETIDO EM: 27/07/2021

APROVADO EM: 19/11/2021 